GEOPHYSICAL RESEARCH LETTERS, VOL. 11, NO. 5, PAGES 485-488, MAY 1984

\title{
CORRELATED SEDIMENT THICKNESS, TEMPERATURE GRADIENT AND EXCESS PORE PRESSURE IN A MARINE FAULT BLOCK BASIN
} \author{
Dallas Abbott ${ }^{1}$, William Menke ${ }^{1}$, Michael Hobar ${ }^{2}{ }^{2}$, Roger $N$. Anderson ${ }^{2}$, and
Robert W. Embley \\ ${ }^{1}$ College of Oceanography, Oregon State University, Corvallis OR 97331 \\ 2Lamont-Doherty Geological Observatory, Palisades NY 10964

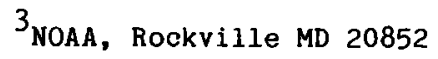

\begin{abstract}
Measurements of temperature gradient and excess pore pressure in the surficial sediment of a fault block basin in the Guatemala Basin correlate with sediment thickness. The temperature gradient is smaller and the excess pore pressure gradient is more negative in areas of thinner sediment. This correlation is explained by postulating downward pore water advection within the sediments, with flow velocities on the order of $10^{-9}$ to $10^{-8} \mathrm{~m} / \mathrm{s}$ in the thinnest sediments and much less flow in the thickest sediments. Sediment physical properties and pore water chemistry also support this interpretation. Since the conductive heat flow of the basin as a whole is less than one third that predicted by sea floor spreading models, the oceanic basement may be the site of a vigorous hydrothermal circulation system. The pore water advection in the sediments may be driven by this larger scale circulation.
\end{abstract}

\section{Introduction}

We present temperature and excess pore pressure data from a sediment filled basin that overlies $26 \mathrm{~m} . \mathrm{y}$. Old Pacific plate crust in the Guatemala Basin (Figure 1). The basin is approximately $75 \mathrm{~km}$ wide, and is bounded by two sets of abyssal hills that are probably fault controlled. Seismic profiling indicates that the sediment is about $300 \mathrm{~m}$ thick in the deeper, eastern part of the basin (Figure 2). The sediment, as determined from piston coring, is mostly siliceous hemi-pelagic ooze, with some interbedded rhyolitic ash layers derived from Central Americal volcanoes $700 \mathrm{~km}$ to the east. Ash layers are also observed at greater subbottom depth at nearby Deep Sea Drilling site 495 [Aubuoin et al., 1983], suggesting that the reflectors in the seismic profiler record (Figure 2) also correspond to ash layers.

Measurements of temperature gradient and thermal conductivity enable us to determine an average conductive heat flow of $30 \mathrm{~mW} / \mathrm{m}^{2}$ from the sediments in this region. This value is only one third of the value predicted by plate tectonic models of $26 \mathrm{~m} . \mathrm{y}$. old oceanic I ithosphere [McKenzie and Sclater, 1969], leading us to conclude that heat is being removed from the orust underlying the basin by processes other than conduction. We assume that convection of water within the highly permeable

Copyright 1984 by the American Geophysical Union.

Paper number $4 \mathrm{~L} 6067$. 0094-8276/84/004L-6067\$03.00 oceanic crust is responsible for this thermal anomaly, since this process is known to affect heat flow in crust of age up to $80 \mathrm{~m} . \mathrm{y}$. [Embley et al., 1983].

The sediments are several orders of magnitude less permeable than the oceanic grust ( $2 \times 10^{-16}$ $\mathrm{m}^{2}$ for sediment compared to $10^{-12} \mathrm{~m}^{2}$ for basaltic crust) [Abbott et al., 1981; Anderson and Zoback, 1982]. Therefore, most of the circulation takes place in the basement, with the sediments playing a largely passive role. One possible circulation pattern, based on the modeling work of Gartling and Anderson [1984] and Elder [1981] is that upwelling warm water is exiting the basement through cracks and vents in a few topographically high regions, and is being replenished by a more widely distributed return flow. As we shall outline below, we believe at least some of this return flow is in the form of downward advection of pore fluids through the thinner sediment layers.

We measured temperature gradient (that is, conductive heat $\mathrm{flow}$ ) and excess pore pressure gradient at about 35 sites in the sediment basin (Figure 1). The measurements were made with a digital heat flow probe of standard design, equiped with a differential pressure transducer to measure non-hydrostatic pressure differences between the sediment at the bottom of the probe (at about $2 \mathrm{~m} \mathrm{depth}$ ) and the ocean-sediment

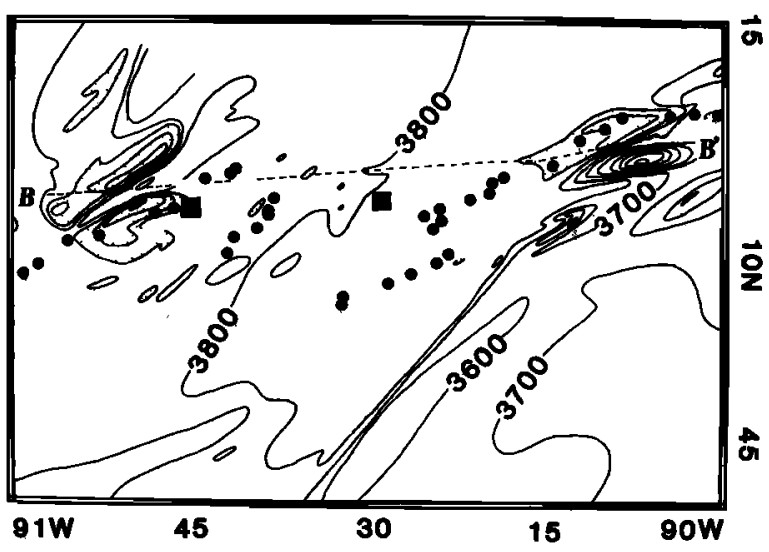

Fig. 1. Bathymetric map showing locations at which temperature and excess pore pressure data (circles) and piston cores (squares) were collected. These data are shown in Figure 3, projected onto cross-section $\mathrm{BB}^{\prime}$ along 1 ines parallel to the regional geologic trends, approximately $\mathrm{N} 35^{\circ} \mathrm{E}$. Contours in nominal meters. 

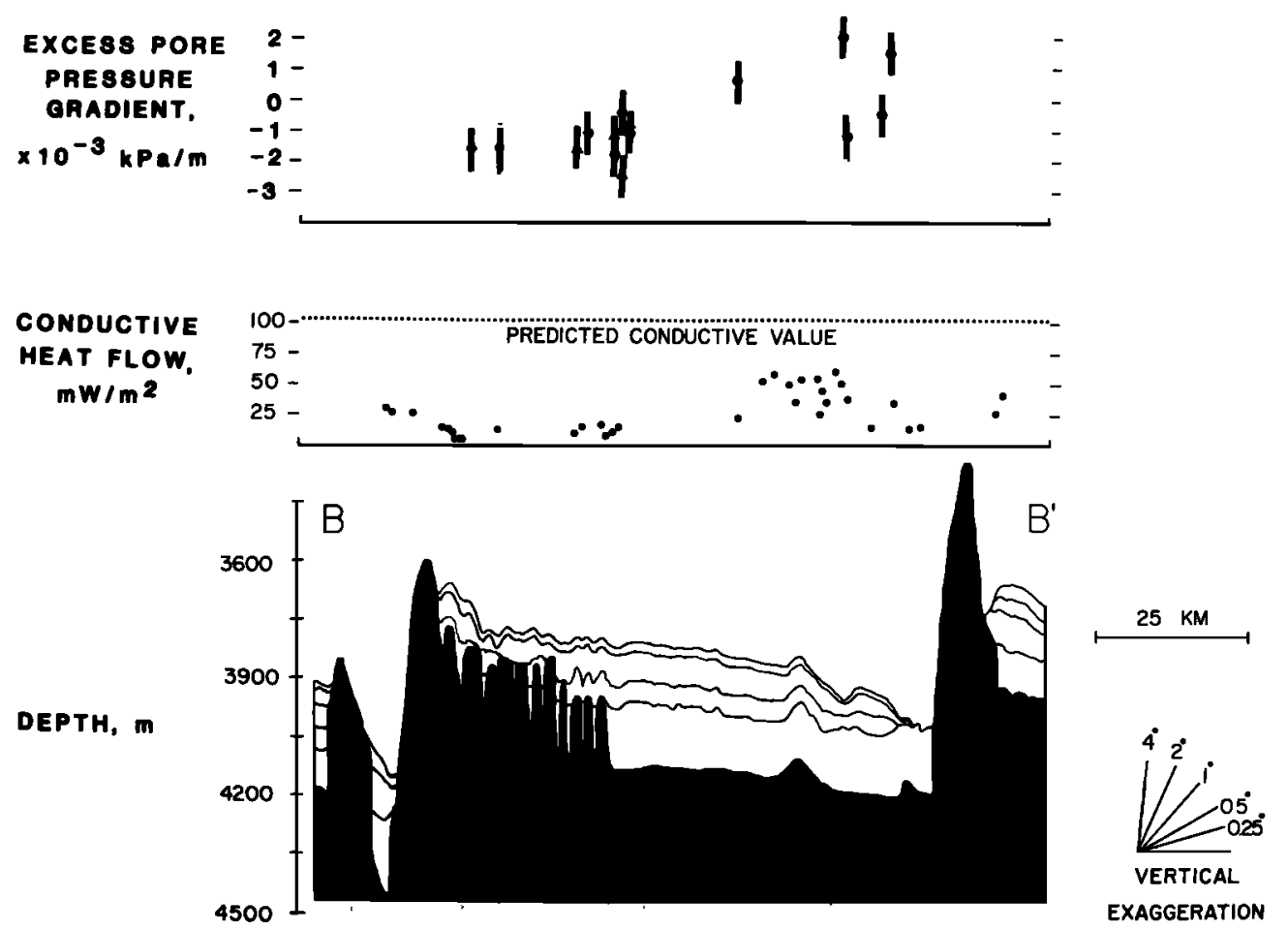

Fig. 2. Excess pore pressure gradient (top graph), conductive heat flow (related to temperature gradient, middle graph) and sketch of seismic profiler record (bottom graph) projected along line $\mathrm{BB}^{\prime}$ of Figure 1 . Note that large negative excess pore pressures and small heat flow values occur in the more thinly sedimented regions on the west side (left) of the basin. Standard errors for the heat flow data are typically less than $5 \mathrm{~mW} / \mathrm{m}^{2}$ errors for the pore pressure data are larger, perhaps as much as $\pm 0.75 \times 10^{-3} \mathrm{kPa} / \mathrm{m}$. The locations of cores 2 and 3 are noted on the profiler record.

interface. The insertion of the probe into the sediment induces a pressure transient, which asymptotically decays to the in situ excess pore pressure. We determined this asymptote by fitting computer generated models of pressure decay to the data (Figure 3), where the zero pressure baseline is determined by suspending the entire probe in sea water just above the ocean bottom. The errors in estimating the pore pressure by this method are quite large, perhaps as much as $\pm 0.75 \times 10^{-3} \mathrm{kPa} / \mathrm{m}$ (compared to $\mathrm{a}_{3}$ signal with a maximum amplitude of $3.0 \times 10^{-3}$ $\mathrm{kPa} / \mathrm{m})$, so our interpretations a 2 only based on the average of groups of neighboring

measurements. The permeability of the sediment can also be estimated from the pressure decay rate.

We also collected several piston cores from which porosity, shear strength, and pore water calcium and magnesium concentrations were measured. These physical properties can be influenced by advecting pore water.

\section{Correlated Heat F1ow and Excess Pore Pressure}

We first correct the temperature gradient data for variations in the thermal conductivity, to yield conductive heat flow. When these data and the excess pore pressure data are projected onto a line crossing the sediment basin, an interesting pattern emerges. The conductive heat flow increases from an average of about 15
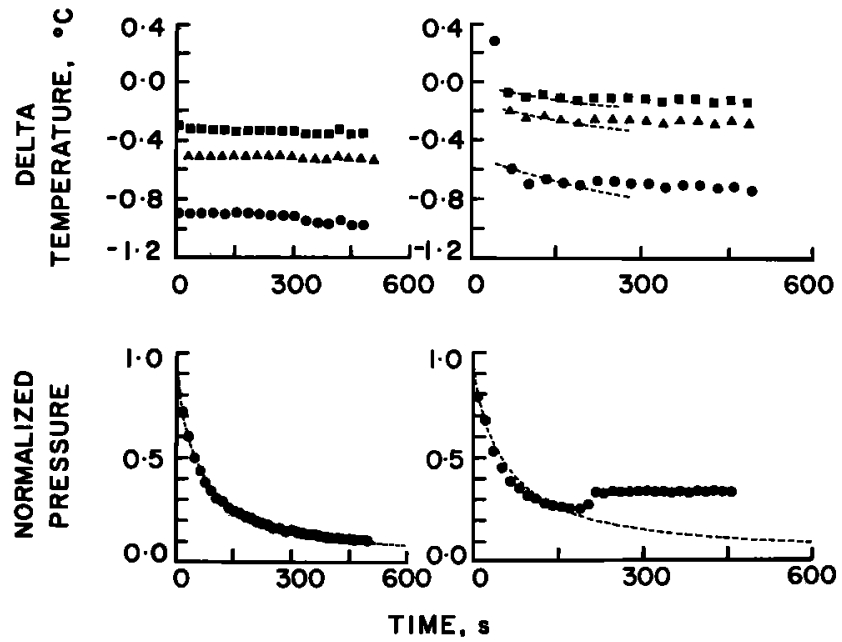

Fig. 3. Temperature and excess pore pressure data for two deployments of the heat flow probe, which consists of three thermistors and one differential pressure transducer. In the best deployments (left), temperature and pressure transients rapidly decay to their in situ values. In a few poorer deployments (right), both temperature and pressure are disturbed by vibrations transmitted along the cable connecting ship and probe, which can clog the pressure ports. Pore pressures are determined by fitting exponentially deaying curves (dashed) to the data. 


\section{CORE 2}

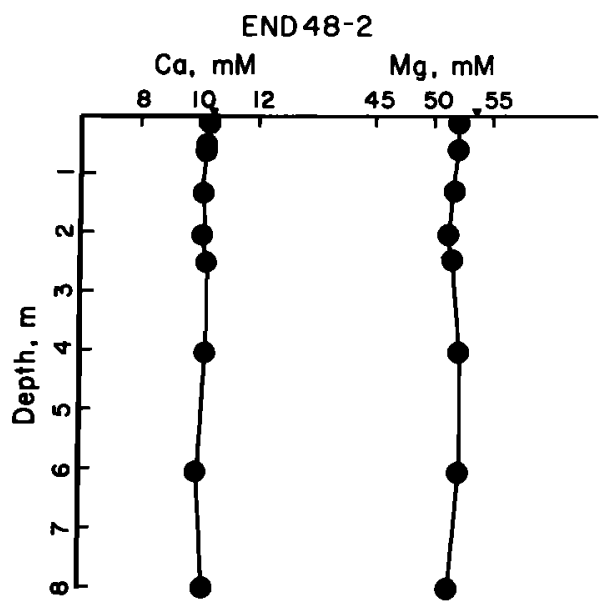

\section{CORE 3}

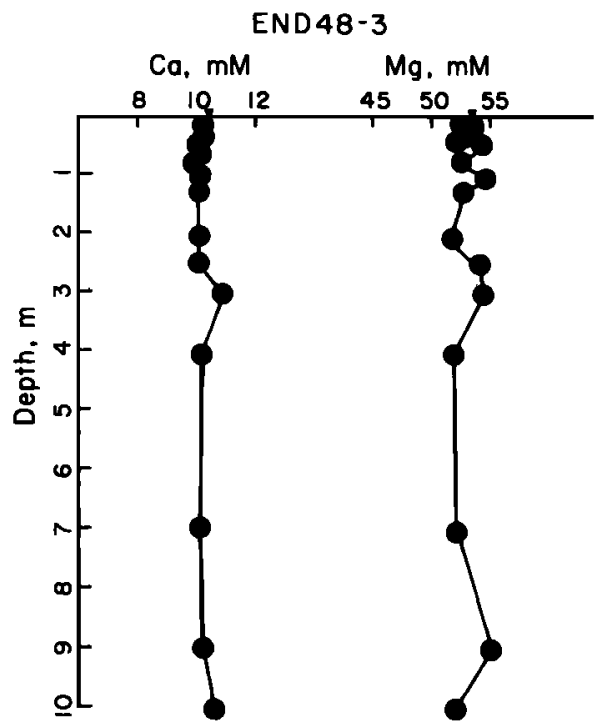

Fig. 4. Calcium and magnesium concentration as a function of depth in the pore water of core 2 (left, thin sediment) and core 3 ( $r$ ight, thick sediment). The concentrations of $\mathrm{Ca}$ and $\mathrm{Mg}$ are very close to sea water composition in both cores, indicating that the pore water has not yet equilibrated with the sediment. Error bars (not plotted) are smaller than the symbol size. Note the greater variability in core 3, which is from an area of thicker sediment. Advection rates are thought to be lower in this area, which perhaps permits some degree of equilibration. Data provided by C. Maris [personal communication].

$\mathrm{mW} / \mathrm{m}^{2}$ over the thinner sediment at the east of the basin, to an average of about $50 \mathrm{~mW} / \mathrm{m}^{2}$ in the more thickly sedimented western part. The excess pore pressure gradient averages about $-1.0 \times 10^{-3} \mathrm{kPa} / \mathrm{m}$ in the east to an average of about zero in the west. Both the negative pore pressures and low heat flow can be explained by postulating a downward advection of pore fluids in the thinner sediment. Our estimates of pore pressure and permeability (typically $2 \times 10^{-16}$ $\mathrm{m}^{2}$ ), when combined with Darcy's law, imply downward advection rates between $10^{-9}$ and $10^{-8}$ $\mathrm{m} / \mathrm{s}$. These rates are in rough agreement with the flow rate needed for reducing the temperature gradient by the introduction of cold ocean water into the sediments.

\section{Evidence for Advection From Piston Core Samples}

The pore water in the sediments of piston core 2, which sampled the thinner sediment at the west end of the basin, has calcium and magnesium concentrations near that of sea water (Figure 4, C. Maris, personal communication). No chemical equilibration of the pore water with the sediment seems to have taken place, implying a relatively short residence time for water in the sediment column. Modeling of calcium dissolution in sediments implies that adyection velocities on the order of $10^{-11}$ to $10^{-12} \mathrm{~m} / \mathrm{s}$ are needed to prevent equilibration [Abbott et al., 1983]. The chemistry of core 2 therefore supports the hypothesis that advection is occuring in these sediments. We note, however, that the chemistry of the basement pore fluids is unknown. If exchange of water between the basement and the ocean is sufficiently rapid that the basement pore water retains sea water chemistry, then the chemical data could equally well be explained by upward advection.

The pore water chemistry of core 3 , which sampled the thicker eastern sediments, is also close to sea water composition (Figure 4 ). The chemical profiles do, however, show more variation than does the data from core 2 , implying that the advection rates in the thicker sediments are slower than the thinner, a conclusion which supports our inferences from the heat flow and excess pore pressure data.

The sediment sampled by cores 2 and 3 are superficially very similar. For instance, grain size analysis reveals no significant difference in their sediment grain size distributions. Nevertheless, core 2, from the thinner sediments, has a significantly different variation of shear strength with porosity from core 3 (Figure 5). At a porosity of $87.5 \%$, the sediment of core 2 has only one third the strength of the sediment from core 3 . We attribute this difference to the effect of faster water advection in the sediments of core 2 , which we postulate has caused some dissolution at the grain to grain boundaries in the sediment. The hypothesis is supported by the observation that diatoms in core 2 were significantly more dissolved than in core $3[\mathrm{~J}$. Morley, personal communication].

\section{Conclusions}

Convection of water within the fractured ocean

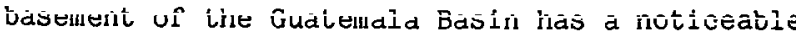




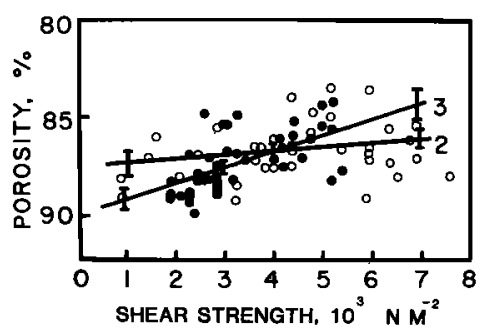

Fig. 5. Correlation of shear strength and porosity for core 2 (thin sediment, open circles) and core 3 (thick sediment, solid circles). Analytical error bars (not plotted) are smaller than the symbol size. Shear strength decreases with porosity in both cores (note straight line fits) but the rate of change is significantly different between the cores (note error bars of fit), even though the two cores are superficially very similar. We attribute the difference in slopes to a slight amount of silica dissolved from core 2 by advecting pore fluids that are not present in core 3 .

effect, not only upon the regionally averaged heat flow, but also upon the chemical and physical properties of sediment overlying the basement. In the sediments we have examined, we find that slow advection of pore water through the sediments changes its excess pore pressure, shear strength and pore water chemistry, and perhaps causes silica dissolution. of course, our surficial measurements do not reveal very much about the overall pattern of convection in sediment and basement. For instance, while we conclude that pore water is advectiong downward near the ocean-sediment interface, we cannot constrain its direction deeper in the sediment: there might be substantial horizontal advection along more permeable layers at depth [Selim, 1975]. This ambiguity emphasizes the need for pressure or flow measurements deep within the sediment or within the basement itself.

Acknowledgements. We thank Marcus Langseth and Robert Stoll for their helpful comments on the manuscript. We thank $C$. Maris for providing the chemical data. We thank William van Stevenick, without whose technical expertise these experiments would have been impossible. We thank the officers, crew and scientists of the $R / V$ Endeavor for their assistance during the cruise. This research was supported by the National Science Foundation under contract 0CE78-20445 and the National Dceanographic and Atmospheric Administration under contract NA90.0060. One of the authors (D.H.A.) was supported by a Columbia University Boris Bakhemeteff Fluid Mechanics Fellowship while performing this research.

\section{References}

Abbott, D.H., W. Menke, M. Hobart and R.N. Anderson, Evidence for excess pore pressure in southwest Indian 0cean sediments, J. Geophys. Res., 86, 813-826, 1981.

Abbott, D.H, W. Menke and R. Mor In, Constraints upon water advection in sediments of the Mariana Trough, J. Geophys. Res., 88, 1075-1093, 1983.

Anderson, R.N. and M.D. Zoback, Permeability, underpressure and convection in the oceanic crust near the Costa Rica Rift, eastern equitorial Pacific, J. Geophys. Res., 87, 2860-2868, 1982.

Aubouin, J., R. von Huene, et al., Site 495: Cocos Plate - Middle American Trench outer slope, Initial Reports of the Deep Sea Drilling Project, 67, U.S. Government Printing Office, Washington, D.C., 79-117, 1983.

Elder, J., Geothermal Systems, Academic Press, Inc., New York, Chapter 10, 1981.

Embley, R.W., M.A. Hobart, R.N. Anderson and D.H. Abbott, Anomalous heat flow in the north Atlantic: a case for continued hydrothermal circulation in $80 \mathrm{~m} . \mathrm{y}$. crust, J. Geophys Res., 88, 1067-1074, 1983.

Garting, D.K. and R.N. Anderson, Finite element model of two layer porous media convection in the oceanic crust and overlying sediments, J. Geophys. Res., in press, 1984.

McKenzie, D.P. and J.G. Sclater, Heat flow in the eastern Pacific and sea floor spreading, Bull. Volcanol., 33, 101-118, 1969.

Selim, H.M., Water flow through a multilayer stratified hillside, Water Resources Res., 11, 949-957, 1975.

(Received February 13, 1984;

revised March 29, 1984;

accepted March 29, 1984.) 